\title{
Aspectual distinctions in Dutch-Ambon Malay bilingual heritage speakers
}

International Journal of Bilingualism 2017, Vol. 21 (2) 178-193 (C) The Author(s) 2015 Reprints and permissions: sagepub.co.uk/journalsPermissions.nav DOI: $10.1177 /|3670069| 56085 \mid 5$ journals.sagepub.com/home/ijb

@SAGE

\section{Francesca R Moro}

Department of Linguistics, Radboud University, the Netherlands

\begin{abstract}
Aims and Objectives/Purpose/Research Questions: This paper investigates the effects of Dutch on the tense-aspect system of heritage Ambon Malay, a variety spoken by Dutch-Ambon Malay bilinguals in the Netherlands. The study asks whether the cross-linguistic contrasts between the two languages - Dutch obligatorily marks past/non-past and finiteness, whereas Ambon Malay lacks a grammaticalized expression of these distinctions - has an effect on the aspectual system of heritage Ambon Malay.

Design/Methodology/Approach: The database for the study consists of video descriptions provided by 32 bilingual speakers (the experimental groups) and by three control groups: 27 homeland speakers of Ambon Malay, 5 first generation speakers of Ambon Malay in the Netherlands (late bilinguals), and 10 monolingual speakers of Dutch.

Data and Analysis: The frequency and distribution of aspect markers is analysed statistically in the four groups.

Findings/Conclusions: The analysis of the data reveals that, under the influence of Dutch, the Ambon Malay progressive marker ada has undergone a shift in temporal status and frequency and it is now interpreted as a marker of present tense, as well as of progressive aspect. The other two aspect markers, the iamitive/perfective su and verbal reduplication (iterative) are used significantly less by heritage speakers.

Originality: This study shows that when a grammatical category is present and productive in the dominant language of a bilingual heritage speaker, but not in the heritage language, there is a great likelihood that it will undergo contact-induced grammaticalization, even in a relatively short time contact situation. The study also shows that input-related factors, such as transparency and phonological salience, contribute to the (in)stability of aspectual forms in the heritage language.

Significance/Implications: This finding has implication for the incomplete acquisition perspective on heritage languages, which sees these languages as grammatically simplified systems (see, e.g., Montrul, 2009; Polinsky, 2008), because it shows that heritage languages can also gain grammatical distinctions previously absent in the (homeland) language.
\end{abstract}

\section{Keywords}

Ambon Malay, aspect, bilingualism, contact-induced grammaticalization, Dutch, heritage language, progressive marker 


\section{Introduction}

Heritage speakers are a special case of bilingual individuals whose family language is a minority language and who are dominant in the majority language of the national society (Montrul, 2009; Polinsky, 2008; Silva-Corvalán, 1994). These bilinguals are exposed to and use each language in different contexts, and the majority of them experienced a shift in dominant language during adolescence (from the family-heritage language to the national-dominant language). The benefit of studying the heritage speaker population is that we can investigate the type of changes and the mechanisms that operate when two languages of unequal status are spoken in a community for about 50-100 years (2/3 generations). For this reason, many researchers consider heritage languages as 'an experiment in nature - that is, a naturally occurring event that sheds light on the effect of factors that, for ethical or practical reasons, could not be controlled in a laboratory setting' (O'Grady, Kwak, Lee, \& Lee, 2011, p. 224). In other words, heritage languages allow us to study the ontogeny of contact-induced change in a naturalistic setting.

One of the grammatical phenomena that have attracted the most attention in heritage language research is aspect. This category is highly semantically salient and as such it is expected to remain stable even though the means for expressing it may change (Polinsky, 2008, p. 280). If on the one hand the conceptual category of aspect is universal and hence stable, the expression of aspectual contrasts has been shown to be rather unstable in language contact settings, especially in heritage languages. Contact phenomena attested in the aspectual systems of heritage languages are generally of two kinds: decrease in frequency or loss of aspectual distinctions (as reported for heritage Russian in the US by Polinsky, 2008 and Laleko, 2010; for heritage Spanish in the US by SilvaCorvalán, 1994 and Montrul, 2009), and overextension of progressive forms to mark imperfective aspect (as reported for heritage Spanish in the US by Koontz-Garboden, 2004; for heritage Dutch in the US by Brown \& Putnam, to appear; for heritage Mandarin in the Netherlands by Shi, 2011).

In this article, I follow this line of investigation and I explore the effects of contact on the aspectual system of heritage Ambon Malay, the language spoken by the descendants of the 12,500 Moluccans who arrived in the Netherlands in the early 1950s, after the decolonization of Indonesia ${ }^{1}$ (Veenman, 1994). Heritage speakers of Ambon Malay are bilingual in Dutch and Ambon Malay, but have Dutch as their dominant language. Previous studies (Aalberse \& Moro, 2014; Huwaë, 1992; Lekawael, 2011; Moro, 2014; Moro \& Klamer 2015; Tahitu, 1989) have shown that Ambon Malay in the Netherlands is undergoing a substantial number of changes owing to unbalanced bilingualism in general, and to the intense contact with Dutch in particular.

Dutch and Ambon Malay represent an interesting language pair because Dutch obligatorily marks a past/non-past contrast; however, the degree to which aspect is (periphrastically) marked is variable, whereas Ambon Malay lacks a grammaticalized expression of tense, but has a number of optional aspect markers. Furthermore, Dutch has a clear finite/non-finite contrast, with tense morphology (in addition to agreement morphology) instantiating finiteness. This study investigates contact-induced changes in the aspectual system of heritage Ambon Malay by focusing on three main (tense)aspect markers, ${ }^{2}$ namely $a d a$ (progressive), $s u$ (iamitive, perfective), and reduplication (iterative), as illustrated in (1)-(3).

(1) Dia ada masa

3SG PROG cook

'She/he is cooking.' 3

(2) Dia su masa

3SG IAM cook

'She/he has already cooked.' 


\section{(3) Dia masa-masa \\ 3SG ITER-cook \\ 'She/he cooks (repeatedly).'}

The study investigates whether the frequency and the usage of the aspect markers in (1)-(3) differ between homeland (monolingual)speakers in Ambon and heritage (bilingual) speakers in the Netherlands, and whether the aspectual system of Ambon Malay is undergoing restructuring under the influence of Dutch.

This article is organized as follows. The next section gives an overview of the various factors responsible for the restructuring of the aspectual system of contact varieties. This is followed by a description of the main aspectual contrasts expressed in Ambon Malay and Dutch, the two languages of heritage speakers. The following section presents the research questions, the participants and methodology, and the results of the study. Findings are outlined, and the final section then presents conclusions.

\section{The restructuring of aspect in heritage languages}

Recent approaches to heritage languages have identified a number of factors that play a role in shaping heritage grammars (Bylund \& Jarvis, 2011; Koontz-Garboden, 2004; Laleko, 2010; O'Grady et al., 2011; Polinsky, 2008). The first factor, which is directly related to the dominant language, is cross-linguistic influence. Cross-linguistic influence can lead to an increase or to a decrease in the use of specific aspect markers, depending on what is obligatorily encoded in the dominant language of heritage speakers. Studies such as Flecken (2010) have demonstrated that bilingual speakers tend to overtly express the categories that are grammaticalized in their dominant language. Koontz-Garboden (2004), for instance, shows that Spanish-English bilinguals use the progressive aspect more frequently than their monolingual peers, and he argues that this is attributable to the influence of English, a language in which progressive aspect is highly grammaticalized. By contrast, Bylund and Jarvis (2011) show that Spanish-Swedish bilinguals use fewer progressive forms than their monolingual peers, and they argue that this is attributed to the fact that bilinguals are affected by the Swedish-like tendency to attend to the telicity rather than the ongoingness of events. Intense cross-linguistic influence can ultimately lead to contact-induced grammaticalization, a well-known process whereby bilingual speakers replicate a prominent (obligatory) category of the dominant language (e.g. tense) using the 'linguistic material' of the heritage language (e.g. an aspect marker) (Heine \& Kuteva, 2005).

There are other factors shaping heritage languages that are not directly related to the dominant language, but are related to the effects of bilingualism and to limited exposure to the heritage language (especially after adolescence). These factors, which are sometimes referred to as language 'internal' factors, are indeterminacy, frequency and acoustic salience (Laleko \& Polinsky, 2013; Montrul 2009; O’Grady et al., 2011). Indeterminacy refers to forms that have a non-transparent form-meaning mapping because they are optional and functionally ambiguous (Laleko \& Polinsky, 2013). For instance, Montrul (2009) shows that heritage speakers of Spanish make more errors with the imperfective than with the preterite, and she (p. 266) argues that this is attributable to the fact that 'the imperfect [...] represent[s] [a] relation of one form to several meanings, and [is] thus more inherently complex because the mappings are not always transparent'. Another example is that reported by Ma (2006), who shows that the functional-semantic ambiguity of the Mandarin perfective aspect marker -le is problematic for English L2 learners. The author argues that L2 learners tend to overuse - $l e$ because they reanalyze this form as a past tense marker (on the model of English). Indeterminacy, thus, can lead to destabilization of both the original frequency and the 
function of a form. In heritage languages, indeterminate forms tend to become unstable because their successful acquisition depends on frequent exposure But frequent exposure is precisely what heritage speakers lack(ed), as they grew up acquiring another (dominant) language since early childhood (O’Grady et al., 2011).

Unlike indeterminacy, input frequency and acoustic salience contribute to the stability of forms because they increase availability in the input (O'Grady et al., 2011). In other words, if a form is always there and is highly audible, there are more chances that it will be retained. O'Grady et al. (2012) present data showing that heritage speakers of Korean perform better in a comprehension task when the acoustic salience of case markers is manipulated so as to increase the volume, the duration, and the pitch. Another example is Aalberse and Moro (2014), who argue that the Ambon Malay aspect marker $a d a$ is stable in the heritage variety, despite being semantically indeterminate (see the next section for a detailed discussion of $a d a$ ). They propose that, when semantic indeterminacy is compensated for by frequency and phonological salience (ada carries stress and contains two high sonority vowels), the form may undergo functional extension rather than loss.

Finally, other factors may play a role in the restructuring of the aspectual system. For instance, Polinsky (2008) identifies loss of morphology and the reduced lexical competence of heritage speakers as two possible causes affecting the expression of aspect in heritage Russian. Heritage speakers of Russian retain just one member of an aspectual pair (perfective-imperfective), independent of aspect. It is hard to predict which form will be retained, but factor such as frequency and telicity seem to play a role. Reduced lexical competence may account also for the limited number of reduplicated verbs in heritage Mandarin, as reported by Shi (2011). Thus, morphological complexity and lexical knowledge can also have repercussions for the heritage verbal system.

To summarize, cross-linguistic influence from the dominant language can lead either to loss or to the overextension of forms in the heritage language, depending on which tense-aspectual notions are grammaticalized. Language-internal factors, such as indeterminacy, frequency and phonological salience, can also contribute to the (in)stability of the frequency and the function of aspectual forms.

\section{Tense-aspect in Ambon Malay and Dutch}

This section presents the Ambon Malay grammatical markers that will be the subject of investigation in this study (section 'Aspect in Ambon Malay'). In order to provide the reader with an overview, I will also briefly describe how tense-aspectual distinctions are marked in Dutch, the dominant language of heritage speakers (section 'Tense-aspect in Dutch'). An interim summary is presented at the end of this section.

\section{Aspect in Ambon Malay}

Ambon Malay does not mark tense, but it marks grammatical aspect analytically by means of two aspect particles, $a d a$ (section 'The marker ada') and $s u$ (section 'The marker su') and reduplication (see final sub-section). Aspect marking is optional in Ambon Malay and the correct temporal interpretation of the utterance is often inferred from the (extra-) linguistic context (van Minde, 1997, p. 189).

The marker ada. Ada is mainly a marker of progressive and continuous aspect ${ }^{4}$ (van Minde, 1997, p. 191), but in some contexts it can also have a perfect meaning. With predicates describing a process, such as activities and accomplishments, ${ }^{5}$ ada indicates the 'ongoingness' of the event, as illustrated in (4). 
(4) katong ada dudu tado-tado dong datang bahonge sa. We were sitting very quietly and then they came to disturb us. (van Minde, 1997, p. 191)

When ada precedes verbs that have an inherent endpoint as part of their lexical meaning, such as accomplishment and achievements, it can carry a perfect meaning (cf. van Minde \& Tjia 2002, p. 293), as illustrated in example (5) ${ }^{6}$ where $a d a$ is not a marker of progressive aspect because the event is punctual (snapping a stick) and it has already happened. In fact, the speaker is able to describe the result of it (the stick has been broken into two pieces).

(5) parampuang ada pata kayo jadi dua
girl PROG break stick become two
'A girl has broken a piece of stick into two.'

The marker su. The marker $s u^{7}$ is a tense-aspect marker whose functions overlap with those of the English perfect (have -ed) and of the adverb 'already'. Dahl has coined the term 'iamitive' (from Latin iam 'already') to refer to this type of tense-aspect, which is very common in languages of Southeast Asia (see Olsson, 2013, for a study of iamitives in a cross-linguistic perspective). Su, however, is more than a tense-aspect marker and some of its functions fall within the realm of modality and discourse (see van Minde \& Tjia 2002 for a full account of the functions of $s u$ ). Generally speaking, the main function of $s u$ is to contrast a state of affairs to a previous one. An example of $s u$ is given in (6).

(6) Dong su makang deng balong galap lai 3PL IAM eat and not.yet dark also They have (already) eaten and it is not dark yet. (van Minde, 1997, p. 229)

Reduplication. In Ambon Malay, verbal reduplication has several functions, including iterative, increased degree and plurality (van Minde, 1997, pp. 119-130). The main function of reduplication is to mark iterative aspect, as shown in (7).

(7) Tikus toki-toki $\quad$ kue
mouse ITER-knock cake
'The mouse knocks (repeatedly) on the cake.'

\section{Tense-aspect in Dutch}

This section gives an overview of the main tense-aspect distinctions encoded in Dutch. This description is meant to orientate the reader in the understanding of possible cross-linguistic influence from Dutch onto heritage Ambon Malay. For the sake of convenience, this section is organized according to function.

Present tense. In Dutch, present and past tense marking is obligatory and it is expressed by means of verbal inflection. The present tense is used even more extensively than in English, in fact it is the most usual way of expressing an action that is still continuing into the present, as in Ik woon (PRESENT) al tien jaar hier 'I have lived (PERFECT) here for ten years' (Donaldson, 2008, p. 184). 
Past tense. Dutch has two ways to mark past tense, the 'imperfectum' and the perfect. The imperfectum is expressed by means of verbal inflection and it is used for describing a series of events in the past (Donaldson, 2008, p. 185). The perfect is encoded by means of a verbal auxiliary, 'be' for unergative verbs and 'have' for ergative verbs, and the past participle (Donaldson, 2008, p. 176), as illustrated in (8).

(8) John is gevallen. Max heeft hem geduwd John be.3sg fall.PST.PTCP Max have.3sG him push.PST.PTCP 'John has fallen. Max has pushed him' (Boogaart, 1999, p. 66)

Progressive aspect. Dutch progressive aspect is marked by the auxiliary verb 'be' and the aan het + infinitive construction (Boogaart, 1999, p. 167-204; Flecken, 2010, p. 189-195), as illustrated in (9).

(9) Ik ben aan het lezen

$1 \mathrm{sg}$ be.1sg at art.indf read-inf

'I am reading' (Flecken, 2010, p. 82)

Additionally, posture verbs such as zitten 'sit', staan 'stand', liggen 'lie', and the adjective bezig 'busy', can occur with an infinitive to convey a progressive meaning.

\section{Interim summary}

The main differences between Ambon Malay and Dutch are summarized in Table 1. These involve the expression of tense. In fact, Dutch obligatorily marks tense (past/non-past, whereas Ambon Malay does not. In both languages, progressive marking is optional. In Ambon Malay, it is expressed with ada, whereas in Dutch, it is expressed by means of the aan het INF construction and posture verbs. The overt expression of iterative aspect is also optional in both languages; however, Ambon Malay marks iterativity by means of reduplication, whereas Dutch lacks a specific marker and uses adverbs, such as telkens weer 'repeatedly'.

\section{The present study}

\section{The research questions}

We have seen in the previous sections that Ambon Malay and Dutch differ with respect to the encoding of tense-aspect distinctions. Now we may ask more broadly how heritage speakers of Ambon Malay, who are bilingual in Dutch and Ambon Malay, but whose dominant language is Dutch, deal with these two sub-systems. I address three specific research questions in this study.

1. Does the aspectual system of heritage Ambon Malay feature innovations?

2. If it does, what are the innovations? Can they be characterized in terms of overextension and/or loss?

3. Do external and/or internal factors, such as cross-linguistic influence from the dominant language and input properties, account for the innovations?

Two predictions can be formulated on the basis of previous studies (see section 'The restructuring of aspect in heritage languages'). First, heritage speakers will tend to overtly express the contrasts 
Table I. Summary of the main tense-aspectual distinction of Ambon Malay and Dutch.

\begin{tabular}{|c|c|c|}
\hline & Ambon Malay & Dutch \\
\hline Present & - & $\begin{array}{l}\text { obligatory, expressed by the stem, stem }+t \text {, } \\
\text { or the infinitive }\end{array}$ \\
\hline (Past) Imperfectum & - & obligatory, expressed by inflection \\
\hline (Past) Perfect & optional, expressed by ada or by su & $\begin{array}{l}\text { obligatory, expressed by 'be/have' and the } \\
\text { past participle }\end{array}$ \\
\hline Progressive & optional, expressed by ada & $\begin{array}{l}\text { optional, expressed by the aan het }+ \text { INF } \\
\text { construction, and posture verbs plus infinitive }\end{array}$ \\
\hline Iterative & optional, expressed by reduplication & optional, not expressed grammatically \\
\hline
\end{tabular}

that are grammaticalized in Dutch (i.e. tense), when speaking Ambon Malay, as they are used to marking these contrasts in the dominant language. Second, heritage speakers will tend to make less use of the forms that are semantically and functionally ambiguous.

In order to answer these questions and test the predictions, this study investigates how the markers $a d a, s u$ and reduplication are used by heritage speakers of Ambon Malay compared to homeland and first generation speakers. It is important to emphasize that aspect marking is optional in Ambon Malay, and that the use of aspect markers is also variable across homeland speakers. Hence, the quantitative comparison will focus on whether the heritage speakers' use of aspect markers falls within the range of variability observed for homeland speakers and not on whether their use of aspect marker is infelicitous ${ }^{9}$ to a monolingual homeland speaker.

\section{Participants}

Four groups of speakers participated in the study:

(a) a test group of adult heritage speakers of Ambon Malay in the Netherlands, all bilingual in Dutch and Ambon-Malay $(n=32)$;

(b) a control group of adult homeland speakers of Ambon Malay living in Ambon, Indonesia, with no knowledge of Dutch $(n=27)$;

(c) a control group of first generation speakers of Ambon Malay who arrived in the Netherlands after puberty and therefore qualify as late bilinguals $(n=5)$;

(d) a control group of adult Dutch speakers with no knowledge of Ambon Malay $(n=10) .{ }^{10}$

More information on the participants is displayed in Table 2.

\section{Methodology}

Every participant performed two tasks: a simultaneous video description task and a video re-telling task. The videos of the simultaneous task were extracted from the episodes a famous German children's series, whose protagonists is a mouse, whereas the videos of the re-telling tasks were selected from the fieldwork material made available by Max Planck Institute for Psycholinguistics, Nijmegen. ${ }^{11}$ In the simultaneous video description task, the participants were asked to describe 14 short videos while watching them (in a fashion similar to the running commentary of a football match). In the video re-telling task, the participants were asked to watch 29 short video clips. ${ }^{12}$ They watched two clips per time, and then described what they had just seen. The data were 
Table 2. Information about the number, gender and age of the participants in the four groups.

\begin{tabular}{llrrrrl}
\hline & Group & No. of speakers & Female & Male & Average age & Standard deviation \\
\hline Test group & Heritage & 32 & 16 & 16 & 43.7 & 12.6 \\
Control groups & Homeland & 27 & 16 & 13 & 43.0 & 18.3 \\
& First generation & 5 & 3 & 2 & 66.6 & 20.6 \\
& Dutch & 10 & 6 & 4 & 40.0 & 21.7 \\
\hline
\end{tabular}

elicited orally and the videos in both tasks were played on a laptop in front of the participant. The homeland, first and heritage speakers performed the tasks in Ambon Malay, whereas Dutch speakers performed the tasks in Dutch.

These two tasks were chosen because they have different advantages. The simultaneous video description task leaves the participant little time to rely on meta-linguistic awareness, and therefore guarantees spontaneous data. However, in the simultaneous video description task it was not possible to control for how the participant conceptualized the event (did she perceive the situation as an activity or an accomplishment?). The data obtained by means of this task were used to calculate the percentage rate of aspect markers for every speaker based on the total number of predicates. An independent sample $t$-test ${ }^{13}$ was conducted to compare the speakers' rates and to determine differences between the homeland group and the heritage group with respect to aspect marking.

The problem of controlling for the type of situation described was overcome in the re-telling task because in this task the participants described the video clips after having watched them. The 29 video clips were categorized as clearly displaying an activity (5 clips), an accomplishment (10 clips) or an achievement (14 clips). ${ }^{14}$ The activity clips displayed events that were ongoing and did not have an endpoint (e.g. swimming,). The accomplishment clips displayed events that involved duration but had a clear endpoint (e.g. cut off the branch of a tree). The achievement clips displayed punctual events with a clear endpoint (e.g. kicking a ball once). The data were coded for the presence or absence of $a d a, s u$ and reduplication in the target descriptions. A mixed effects logistic regression in R (using the glmer package) was used to assess the effect of group (homeland, first generation, and heritage) and video clip type (activity, accomplishment, and achievement) with speaker as a random effect.

\section{Results}

Results of the simultaneous video description task. Overall, homeland speakers and first generation speakers are more homogeneous in their output, showing a similar rate of $a d a, s u$ and reduplication, whereas heritage speakers are skewed toward ada (Figure 1). Given the small sample size of the first generation group, the comparison with this group will be qualitative in nature.

An independent sample $t$-test revealed that in the heritage group ada is used significantly more often $(M=13.75, S D=9.32 ; t(37.575)=5.768, p<0.001, r=0.68$, equal variances not assumed $)$ than in the homeland group $(M=3.74, S D=2.82)$. If we take the value of the $75 \%$ percentile in the homeland group as cut-off point (0.048), then 27 heritage speakers out of 32 have a rate of ada that is higher than this value. In contrast, $s u$ is used significantly less frequently in the heritage group $(M=3.43$, $S D=4.43)$ than in the homeland group $(M=7.22, S D=7.48 ; t(40.693)=-2.308, p=0.026, r=0.36$, equal variances not assumed).If we take the value of the $25 \%$ percentile in the homeland group as cut-off point (0.02), then only 13 heritage speaker out of 32 have a rate of $s u$ higher than this value. Reduplication also shows a significant decrease in the heritage group $(M=1.46, S D=1.96)$ compared to the homeland group $(M=4.44, S D=2.60 ; t(47.758)=-4.816, p<0.001, r=0.57$, equal variances not 

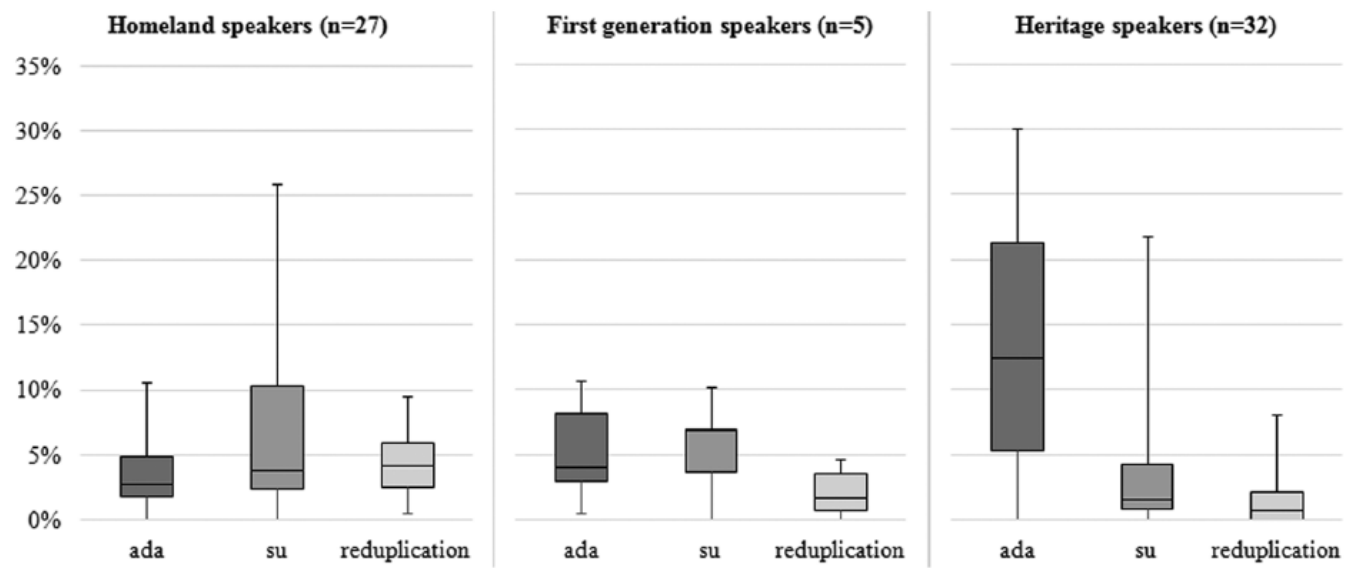

Figure I. Percentage rate of aspect markers in the simultaneous video description of the three Ambon Malay groups.

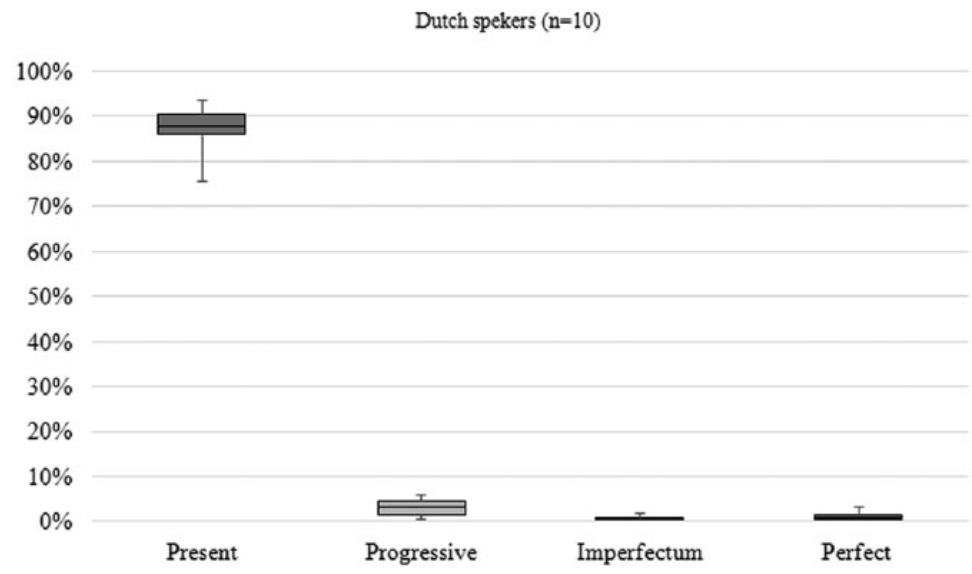

Figure 2. Percentage rate of tense-aspect markers in the simultaneous video description of the Dutch group.

assumed). If we take the value of the $25 \%$ percentile in the homeland group as cut-off point (0.02), then only seven heritage speakers out of 32 have a rate of reduplication higher than this value.

The Dutch group is extremely homogenous in showing a neat preference for present tense marking $(M=87.07, S D=5.44)$, followed by progressive marking $((M=3.31, S D=1.87)$. The other tense-aspect markers occur considerably less frequently. The data are summarized as box plots in Figure 2.

In summary, in the simultaneous video description, homeland and first generation speakers do not have a clear preference and use $a d a, s u$ and reduplication with a similar frequency. In contrast, heritage speakers use $a d a$ more frequently to the detriment of $s u$ and reduplication. Dutch speakers use mainly the present tense.

Results of the video re-telling task. In the re-telling task, the 74 participants described 29 video clips. This yielded a total number of 2146 responses. A total of 150 responses was excluded either 
Table 3. Summary of valid and excluded responses in the video re-telling task.

\begin{tabular}{lllrrr}
\hline Group & No. of speakers & Responses & Activity & Accomplishment & Achievement \\
\hline Heritage & 32 & Valid & 155 & 301 & 405 \\
& & Excluded & 5 & 19 & 43 \\
Homeland & 27 & Valid & 132 & 265 & 345 \\
& & Excluded & 3 & 5 & 33 \\
First generation & \multirow{2}{*}{5} & Valid & 25 & 49 & 59 \\
& & Excluded & 0 & 1 & 11 \\
Dutch speakers & 10 & Valid & 43 & 95 & 132 \\
& & Excluded & 7 & 5 & 8 \\
\hline
\end{tabular}

because the participant did not describe the target event in the clip, or because (s)he described the clip by using a non-target predicate. If, for instance, a participant described the achievement clip showing a boy who kicks a ball (target: to kick the ball) with an activity predicate (to play with the ball), the response was excluded. The summary of valid and excluded responses is displayed in Table 3.

The data show that the marker $a d a$ is more frequent in activities, than in accomplishments and in achievements (see Table 4). This trend is the same in the homeland and in the heritage group, but the frequency of $a d a$ is always higher in the heritage group. Progressive marking is expected with activities and accomplishments because these two situation types have internal duration as they are made of successive phases (Comrie, 1976). A generalized linear mixed effects model was used to assess the effect of group and video clip type on the use of $a d a$ with speaker as a random effect (formula: $a d a \sim$ group + clip type $+(1 \mid$ Speaker)). All groups showed an effect of clip type $(\beta=-0.698, z=-12.766, p<0.001)$ such that all speakers produced more ada when describing activity clips. There is also a significant effect for group $(\beta=0.325, z=3.040, p<0.05)$, such that the heritage group produced more $a d a$ than the other groups. The overall model was significant $\left(\chi^{2}(2)=190.78, p<0.001\right)$ when compared to a null model with only speaker as a random effect.

The data for $s u$ shows that, in the homeland group, $s u$ is more frequent in achievements and in accomplishments than in activities (see Table 5). This trend is expected because accomplishments and achievements have a build in endpoint and are therefore more likely to be seen as completed situations in the past (Comrie, 1976). It is hard to establish whether the heritage group follows this trend owing to the paucity of tokens. What can be said with certainty, is that the frequency of $s u$ is much lower in the heritage group, where only one token is found, than in the to the homeland group. A generalized linear mixed effects model was used to assess the effect of group and video-clip type on the use of $s u$ 'IAM' with speaker as a random effect (formula: $s u \sim$ group + clip type + (1 Speaker)). There is only a significant effect for video-clip type $(\beta=-0.4501, z=-2.761, p<0.05)$, such that achievement verbs are more likely to be marked by su 'IAM', but no effect for group. The overall model is significant $\left(\chi^{2}(2)=9.4701, p<0.05\right)$, when compared to the null model.

Reduplication is the least frequent of all markers in the three groups (see Table 6). There is only one token in the heritage group, whereas it is completely absent in the first generation group. In the homeland group, reduplication seems to be more frequent in activities and in accomplishments. This trend is expected because both activities and accomplishments describe a process that extends over a period of time. A generalized linear mixed effects model was used to assess the effect of group and video-clip type on the use of reduplication with speaker as a random effect (formula: reduplication $\sim$ group + clip type $+(1 \mid$ Speaker $))$ ). There is only a significant effect for group $(\beta=-0.8882, z=-2.746, p<0.05)$, such that homeland speakers use more reduplicated verbs than the 
Table 4. Frequency of ada in activities, accomplishments and achievements.

\begin{tabular}{lllll}
\hline Ada & & $\begin{array}{l}\text { Activity } \\
(5 \text { clips })\end{array}$ & $\begin{array}{l}\text { Accomplishment } \\
(10 \text { clips })\end{array}$ & $\begin{array}{l}\text { Achievement } \\
\text { (14 clips) }\end{array}$ \\
\hline Homeland $(n=27)$ & Tokens & 44 & 31 & 22 \\
First generation $(n=5)$ & \% within group & $33.3 \%$ & $11.7 \%$ & $6.4 \%$ \\
& Tokens & 12 & 3 & 8 \\
Heritage $(n=32)$ & \% within group & $48.0 \%$ & $6.1 \%$ & $13.6 \%$ \\
& Tokens & 89 & 84 & 64 \\
& \% within group & $57.4 \%$ & $27.9 \%$ & $15.8 \%$ \\
\hline
\end{tabular}

Table 5. Frequency of su in activities, accomplishments and achievements.

\begin{tabular}{lllll}
\hline Su & & $\begin{array}{l}\text { Activity } \\
(5 \text { clips })\end{array}$ & $\begin{array}{l}\text { Accomplishment } \\
(10 \text { clips })\end{array}$ & $\begin{array}{l}\text { Achievement } \\
\text { (14 clips })\end{array}$ \\
\hline Homeland $(n=27)$ & Tokens & 1 & 11 & 16 \\
First generation $(n=5)$ & \% within group & $0.8 \%$ & $4.2 \%$ & $4.6 \%$ \\
& Tokens & 0 & 1 & 3 \\
Heritage $(n=32)$ & \% within group & $0.0 \%$ & $2.0 \%$ & $5.1 \%$ \\
& Tokens & 0 & 0 & 1 \\
& \% within group & $0.0 \%$ & $0.0 \%$ & $0.2 \%$ \\
\hline
\end{tabular}

Table 6. Frequency of reduplication in activities, accomplishments and achievements.

\begin{tabular}{lllll}
\hline Reduplication & & $\begin{array}{l}\text { Activity } \\
(5 \text { clips })\end{array}$ & $\begin{array}{l}\text { Accomplishment } \\
(10 \text { clips })\end{array}$ & $\begin{array}{l}\text { Achievement } \\
\text { (14 clips) }\end{array}$ \\
\hline Homeland $(n=27)$ & Tokens & 2 & 8 & 1 \\
& \% within group & $1.5 \%$ & $3.0 \%$ & $0.3 \%$ \\
First genernation $(n=5)$ & Tokens & 0 & 0 & 0 \\
& \% within group & $0.0 \%$ & $0.0 \%$ & $0.0 \%$ \\
Heritage $(n=32)$ & Tokens & 0 & 1 & 0 \\
& \% within group & $0.0 \%$ & $0.3 \%$ & $0.0 \%$ \\
\hline
\end{tabular}

other two groups, but no effect for video-clip type. The model is significant $\left(\chi^{2}(2)=14.738, p<0.001\right)$, when compared to the null model.

The results of the Dutch group are summarized together in Table 7. Dutch speakers shows an overall preference for present tense in all situation types; the imperfectum and the perfect are used mostly with achievement predicates, whereas the progressive was used only with activity predicates.

\section{Discussion}

The results of the simultaneous video description task show that, when compared to homeland speakers, heritage speaker use $a d a$ with a higher frequency, but $s u$ and reduplication with a lower frequency. The video-retelling task confirmed these results but it also provided an additional piece of information. The strong association of $a d a$ with activity predicates tell us that $a d a$ is still 
Table 7. Frequency of reduplication in activities, accomplishments and achievements. ${ }^{15}$

\begin{tabular}{lllll}
\hline Dutch $(n=10)$ & $\begin{array}{l}\text { Activity } \\
(5 \text { clips })\end{array}$ & $\begin{array}{l}\text { Accomplishment } \\
(10 \text { clips })\end{array}$ & $\begin{array}{l}\text { Achievement } \\
\text { (14 clips) }\end{array}$ \\
\hline Present & Tokens & 28 & 85 & 118 \\
& \% within group & $65.1 \%$ & $89.5 \%$ & $89.4 \%$ \\
Imperfectum & Tokens & 0 & 1 & 4 \\
Perfect & \% within group & $0,0 \%$ & $1.1 \%$ & $3.0 \%$ \\
& Tokens & 0 & 0 & 2 \\
Progressive & \% within group & $0.0 \%$ & $0.0 \%$ & $1.5 \%$ \\
& Tokens & 10 & 0 & 0 \\
& \% within group & $23.3 \%$ & $0.0 \%$ & $0.0 \%$ \\
\hline
\end{tabular}

a marker of progressive aspect in the heritage grammar. What I would like to argue here is that in heritage Ambon Malay ada has become a marker of present tense (possibly also encoding finiteness) and of progressive aspect. There are three main reasons for this argument: the empirical data, typology of grammaticalization, and a similar type of change in another Malay variety (Sri Lanka Malay).

The empirical data reported in the results sections show that the overextension of ada in heritage Ambon Malay is arguably related to the Dutch present tense, rather than to the progressive or to the perfect. In fact, even though the functions of $a d a$ and those of the Dutch progressive and perfect overlap, the frequency of ada in heritage speakers is much higher than the frequency of either of these two forms in Dutch. In both tasks, Dutch speakers showed an overall preference for present tense, which is indeed the prototypical tense used to describe events (Comrie, 1976, p. 66). Now, even though heritage speakers performed the task in Ambon Malay, the concepts of tense and finiteness are highly automatized in their minds, as they encode them when they speak Dutch (their dominant language). Since we know that speakers tend to overtly express the contrasts that are grammaticalized in their languages, it is plausible to assume that heritage speakers have selected the Malay element $a d a$ to overtly express the present tense function. Furthermore, since Dutch expresses finiteness by means of verbal agreement and tense inflection, ada may actually be also encoding finiteness, another feature that is grammaticalized and highly prominent in the dominant language.

The second argument in support of the reanalysis of $a d a$ as a present-tense marker comes from grammaticalization theories (Bybee, Perkins, \& Pagliuca, 1994, pp. 127-144; Hengeveld, 2011, p. 590). The semantic change from progressive to present is a well-known grammatical change that involves desemanticization and functional expansion. Hengeveld (2011, p. 590) explains that the progressive may be interpreted as present under the following conditions: the progressive describes a situation that occurs at a reference time, when the reference time coincides with the speech moment, the present-tense interpretation is likely to arise. If this interpretation becomes dominant, the form acquires the new present tense meaning (the progressive meaning can either disappear or it can remain available). This development in heritage Ambon Malay is a clear instance of contactinduced grammaticalization, whereby a language-internal process (change from progressive to present) is brought about by language contact (Heine \& Kuteva, 2005). Finally, the shift in temporal status and frequency of $a d a$ is consistent with a change that occurred in another radical heritage variety, namely Sri Lanka Malay. Owing to intense contact with Tamil and Sinhala (about 350 years), Sri Lanka Malay has reanalysed $a d a$ as an (almost) obligatory present tense marker 
(Slomanson, 2006, 2011). ${ }^{16}$ Another potentially significant parallel between these two heritage varieties is that, under the influence of Dravidian languages, Sri Lanka Malay has developed an explicit finite/non-finite contrast that is instantiated by tense morphology (Slomanson, 2006). One could speculate that Ambon Malay in the Netherlands is undergoing a similar development owing to the intense contact with Dutch, a language where finiteness is obligatorily encoded on the verb by means of agreement and tense-aspect marking.

The lower frequency of $s u$ and reduplication in heritage speakers relates to semantic indeterminacy and possibly also to low acoustic salience (for $s u$ ), and to low frequency in the input (for reduplication). As we have seen above, non-transparent forms are vulnerable in heritage language grammars. The form $s u$ is semantically non-transparent because, in addition to the perfect meaning, it carries a modal component of expectation. In order to correctly use $s u$, speakers need to take into account expectations associated with the situation, with the cultural setting or with the common ground of the speaker and the hearer. Furthermore, the form $s u$ is the least audible of all aspect markers because it contains a low sonority vowel (Gordon, Ghushchyan, McDonnell, Rosenblum, \& Shaw, 2012, p. 222) and in fast speech is often reduced to $s o$ or $s$ (van Minde, 1997, p. 228).

Reduplication is also indeterminate because it is used to convey several meanings, including iterative aspect, plurality, and intensity. In addition to being indeterminate, reduplication also seems to be a low-frequency form in first generation speakers, those who provided the linguistic input to heritage speakers. This low frequency may either be the result of attrition, or it may be a feature of the language variety first generation speakers brought to the Netherlands in 1950s. Be that as it may, indeterminacy and relatively low frequency in the input may have acted in a cumulative way hindering the acquisition of this form by heritage speakers. Furthermore, the findings of the present study together with those of Shi (2011) relative to the avoidance of reduplicated verbs in heritage speakers of Mandarin in the Netherlands, suggest that reduplication does pose a problem to heritage speakers whose dominant language lacks this morphological process.

To sum up, the non-transparent form-meaning mapping of $s u$ and reduplication renders the conditions for their usage obscure to heritage speakers, who in turn avoid them. Additional input-related factors, such as low acoustic salience and low frequency, may have hindered the acquisition of these already difficult forms even further.

\section{Conclusions}

This study has illustrated two types of contact-induced changes that have occurred in the aspectual system of heritage Ambon Malay, the language variety spoken by Dutch-Ambon Malay bilinguals in the Netherlands. The first innovation concerns the overextension of the marker ada. I argued that in the grammar of heritage speakers $a d a$ is used to convey the present tense function (and possibly also to mark the finiteness contrast), while retaining its (original) progressive function as well. The second innovation concerns the decrease in usage frequency of the iamitive marker $s u$ and of verbal reduplication, a change that is arguably related to language internal factors, such as indeterminacy and low acoustic salience.

There are limitations to this study. First, the analysis is based on data elicited by means of video descriptions. More naturalistic data are needed in order to test whether the changes reported in this study also show up in conversations or in other types of speech. Second, a broader sample of first generation speakers would be highly desirable in order to establish with certainty whether the innovations are characteristics of heritage speakers only, or also of first generation speakers (late bilinguals). 


\section{Acknowledgements}

Parts of this paper were presented at the Workshop 'Structural Change in Heritage Languages' in Noordwijkerhout, The Netherlands, 23-25 January 2013, and at the 'International Symposium on Malay/ Indonesian linguistics (ISMIL), in Procida, 13-15 June 2014. I wish to thank the audiences at these occasions for their valuable input. In addition, I would like to thank Harald Hammarström, Pieter Muysken, Suzanne Aalberse, Carlos Gussenhoven and Bob Borges and two anonymous reviewers for their extremely useful comments on earlier versions of this paper. Any remaining errors are my responsibility.

\section{Declaration of conflicting interests}

The author(s) declared no potential conflicts of interest with respect to the research, authorship, and/or publication of this article.

\section{Funding}

The author(s) received no financial support for the research, authorship, and/or publication of this article.

\section{Notes}

1. Many Moluccans who arrived in the Netherlands spoke Tangsi Malay, a Malay variety largely based on Ambon Malay with some Javanese and Dutch elements (Adelaar \& Prentice, 1996).

2. Pure tense is expressed by time adverbs if required.

3. Abbreviations used in this article are: $\mathrm{ART}=$ article, $\mathrm{IAM}=$ iamitive, $\mathrm{INDF}=$ indefinite, INTENS $=$ intensifier, $I T E R=$ iterative, $\mathrm{PL}=$ plural, $\mathrm{SG}=$ singular, $1=$ first person, $3=$ third person. When not otherwise specified, the examples are from my own dataset.

4. The pre-verbal marker $a d a$ is related to the existential verb $a d a$ 'be(somewhere)'.

5. In the present study, I adopt Vendler's (1957) classification of predicates into states [- telic, - stages], activities [- telic, + stages], accomplishments [+ telic, + stages] and achievements [+ telic, - stages].

6. Examples of $a d a$ with a (resultative) perfect meaning have also been reported for Singapore Chinese Bazaar Malay by Lee, Ping \& Nomoto (2009, p. 308) and Donohue (2011, p. 418).

7. $S u$ is the shortened form of suda. Although the short form is more common, the full form can also occur pre-verbally to mark aspect.

8. Some Dutch verbs ending in -eren or -elen have an inherent iterative meaning, such as klapperen 'to flap' as opposed to klappen 'to applaud' (see http://etymologie.nl/). However, the process that led to the formation of these verbs is no longer productive.

9. Aspect markers are never ungrammatical from a purely syntactic point of view.

10. The Ambon Malay data were collected by the author and by Rosina Lekawael (2011), Jusmianti Garing and Feny Eky; the Dutch data were collected by Rowan Soolsma (2013).

11. The clips were assembled from different field manuals $(1995,2001,2004)$, which are available at http://fieldmanuals.mpi.nl .

12. In both tasks, the video clips were presented in a randomized order.

13. I used the more conservative two-tailed test because I wanted to be neutral with respect to the direction of the effect and take into account any possible difference.

14. The video clips were intermingled with 40 distractors, for a total of 69 video clips.

15. The total for each column does not reach $100 \%$ because some responses contained other types of tenseaspect markers, such as infinitives (19 tokens), future tense ( 2 tokens).

16. Pre-verbal ada in non-past contexts is obligatory for most verbs, provided that another functional marker does not appear in pre-verbal position (Slomanson, 2006, p.143).

\section{References}

Aalberse, S., \& Moro, F. (2014). Stability in Chinese and Malay heritage languages as a source of divergence. In K. Braunmüller, S. Höder, \& K. Kühl (Eds.), Stability and divergence in language contact: factors and mechanisms (pp. 141-162). Amsterdam/Philadelphia: John Benjamins. 
Adelaar, K. A., \& Prentice, D. J. (1996). Malay: its history, role and spread. In S. Wurm, P. Mühlhäusler, \& D. Tyron (Eds.), Atlas of languages of intercultural communication in the Pacific, Asia, and the Americas (pp. 673-693). Berlin: Mouton de Gruyter.

Boogaart, R. (1999). Aspect and temporal ordering: A contrastive analysis of Dutch and English. Unpublished doctoral dissertation, Free University of Amsterdam.

Brown, J., \& Putnam, M. (to appear). Functional convergence and extension in contact: Syntactic and semantic attributes of the progressive aspect in Pennsylvania Dutch. In J. Salmons, \& J. Johannessen (Eds.), Germanic heritage languages in North America: acquisition and change. Amsterdam/ Philadelphia: John Benjamins.

Bybee, J., Perkins, R., \& Pagliuca, W. (1994). The evolution of grammar: tense, aspect, and modality in the languages of the world. Chicago: The University of Chicago Press.

Bylund, E., \& Jarvis, S. (2011). L2 effects on L1 event conceptualization. Bilingualism: Language and Cognition, 14(01), 47-59.

Comrie, B. (1976). Aspect. Cambridge: Cambridge University Press.

Donaldson, B. (2008). Dutch: a comprehensive grammar. London/New York: Routledge.

Donohue, M. (2011). Papuan Malay of New Guinea. In C. Lefebvre (Ed.), Creoles, their substrates, and language typology (pp. 413-436). Amsterdam/Philadelphia: John Benjamins.

Flecken, M. (2010). Event conceptualization in language production of early bilinguals. Utrecht: LOT.

Gordon, M., Ghushchyan, E., McDonnell, B., Rosenblum, D., \& Shaw, P. A. (2012). Sonority and central vowels: a cross-linguistic phonetic study. In S. Parker (Ed.), The sonority controversy (pp. 219-256). Berlin/Boston: Walter de Gruyter.

Heine, B., \& Kuteva, T. (2005). Language contact and grammatical change. Cambridge: Cambridge University Press.

Hengeveld, K. (2011). The grammaticalization of tense and aspect. In H. Narrog, \& B. Heine (Eds.), The Oxford handbook of grammaticalization (pp. 580-594). Oxford: Oxford University Press.

Huwaë, R. (1992). Tweetaligheid in Wierden: het taalgebruik van jongeren uit een Molukse gemeenschap (Unpublished doctoral dissertation). University of Amsterdam.

Koontz-Garboden, A. (2004). Language contact and Spanish aspectual expression: a formal analysis. Lingua, 114(9), 1291-1330.

Laleko, O. (2010). The syntax-pragmatics interface in language loss: Covert restructuring of aspect in Heritage Russian (Unpublished doctoral dissertation). University of Minnesota.

Laleko, O., \& Polinsky, M. (2013). Marking topic or marking case: a comparative investigation of heritage Japanese and heritage Korean. Heritage Language Journal, 10(2), 40-62.

Lee, N., Ping, L., \& Nomoto, H. (2009). Colloquial Singapore English got: functions and substratal influences. World Englishes, 28(3), 293-318.

Lekawael, R. (2011). The development of Moluccan Malay as a heritage language in the Netherlands (Unpublished thesis). Radboud University Nijmegen.

Ma, L. (2006). Acquisition of the perfective aspect marker le of Mandarin Chinese in discourse by American college learners (Unpublished doctoral dissertation). University of Iowa.

Montrul, S. (2009). Knowledge of tense-aspect and mood in Spanish heritage speakers. International Journal of Bilingualism, 13(2), 239-269.

Moro, F. (2014). Resultative constructions in heritage Ambon Malay in the Netherlands. Linguistics in the Netherlands, 31(1), 78-92.

Moro, F., \& Klamer, M. (2015). Give-constructions in heritage Ambon Malay in the Netherlands. Journal of Language Contact, 8, 263-298.

O’Grady, W., Kwak, H., Lee, O., \& Lee, M. (2011). An emergentist perspective on heritage language acquisition. Studies in Second Language Acquisition, 33(2), 223-245.

Olsson, B. (2013). Iamitives: perfects in Southeast Asia and beyond (Unpublished thesis). University of Stockholm.

Polinsky, M. (2008). Without aspect. In G. Corbett, \& M. Noonan (Eds.), Case and grammatical relations (pp. 263-282). Amsterdam/Philadelphia: John Benjamins.

Silva-Corvalán, C. (1994). Language contact and change: Spanish in Los Angeles. Oxford: Clarendon Press. 
Shi, M. (2011) Incomplete knowledge of aspect in heritage speakers of Mandarin Chinese in the Netherlands (Unpublished thesis). Radboud University, Nijmegen.

Slomanson, P. (2006). Sri Lankan Malay morphosyntax. In A. Deumert, \& S. Durrleman (Eds.), Structure and variation in language contact (pp. 135-158). Amsterdam/Philadelphia: John Benjamins.

Slomanson, P. (2011). Dravidian features in the Sri Lanka Malay verb. In C. Lefebvre (Ed.), Creoles, their substrates, and language typology (pp. 383-411). Amsterdam/Philadelphia: John Benjamins.

Soolsma, R. (2013). De progressief in het Nederlands en het Moluks Maleis (Unpublished thesis). Radboud University Nijmegen.

Tahitu, B. (1989). Melaju Sini. Het Maleis van Molukse jongeren in Nederland (Unpublished doctoral dissertation). University of Leiden.

van Minde, D. (1997). Malayu Ambong. Leiden: Research School CNWS.

van Minde, D., \& Tjia, J. (2002). Between perfect and perfective. The meaning and function of Ambonese Malay su and suda. Bijdragen tot de taal-, land-en volkenkunde, 158(2), 283-303.

Veenman, J. (1994). The social integration of Moluccans. Rotterdam: Koninklijke Vermande/ ISEO.

Vendler, Z. (1957). Verbs and times. The Philosophical Review, 66(2), 143-160.

\section{Author biography}

Francesca R Moro is a PhD candidate at Radboud University, Nijmegen, the Netherlands. Her research focuses on Ambon Malay spoken as a heritage language in the Netherlands. She investigates language contact phenomena between Dutch and Ambon Malay in various domains, such as (in)determinate articles, possessive marking, argument marking, aspect and modality. Her research seeks to contribute to our understanding of the language internal factors as well as language external factors that account for innovations in heritage language grammars. She will soon start a postdoc at Leiden University in the NWO Vici Grant Research Project 'Reconstructing the past through languages of the present: the Lesser Sunda Islands'. 